\title{
Investigating the Promise and Pitfalls of Pulse Surveys
}

\author{
Matt I. Brown \\ Geisinger Health System \\ Autism and Developmental Medicine Institute
}

Running Head: PULSE SURVEYS

Address correspondence to:

Matt I. Brown

Geisinger Health System

120 Hamm Drive, Suite 2A, MC 60-36

Lewisburg, PA 17837

mibrown9015@gmail.com

Submitted for peer review at Industrial and Organizational Psychology, 8 September 2020

Please do not copy or cite without the author's permission

Acknowledgements: Special thanks to Rick Flynn for his leadership in working with the hospital leadership team to initiate the pulse survey program. 


\section{Abstract}

Despite the growing popularity and marketing of pulse surveys, there is little research concerning this practice. To this end, this practice forum reports the results of a four-wave pulse survey conducted in a health-care organization. Pulse surveys provided reliable estimates of overall engagement but scores remained stable across eight months. Practically no differences in group scores or trends could be found despite high participation $(\approx 50 \%)$. Item responses displayed little differences between groups (ICC(1) ranging from .03 to .18) and poor discriminant validity. Based on these results, pulse surveys may be adequate for estimating overall employee sentiment but not useful for detecting change over time or differences between groups. These limitations should be considered when designing or implementing pulse surveys.

Keywords: pulse surveys; employee engagement; research-practice gap; survey measurement 
Within organizations, leaders and teams are often tasked with performing at an increasingly faster rate while maintaining high performance. These demands have prompted the popularity of management trends like agility (Cappelli \& Tavis, 2018; Rigby et al., 2020), which emphasizes frequent feedback loops from employees and customers. Not only has this led to the implementation of short, frequent "huddle" meetings (Harrison, 2018) but this has also played a part in the growing popularity of pulse surveys. Pulse surveys are generally defined as a technique to obtain a quicker, yet limited, perspective on workplace climate (Colihan \& Waclawski, 2006). These shorter, more frequent surveys are typically marketed as a supplement or replacement for longer, census-based organizational surveys. Accounts of successful pulse survey programs have appeared in popular publications such as the Wall Street Journal (Silverman, 2014) and the Harvard Business Review (Power, 2016). In addition, advances in survey technologies have made it easier for companies to quickly construct and deploy low cost employee surveys (Macey \& Fink, 2020). These factors, along with a general dissatisfaction with large-scale organizational surveys (e.g., Cappelli, 2020), have made pulse surveys an attractive alternative for driving employee engagement (Welbourne, 2016).

Although pulse surveys are widely marketed by third-party vendors (e.g., TINYpulse, n.d.) and adopted by prominent organizations (e.g. Amazon: Kim, 2018), there is little existing research available for scientist-practitioners concerning this practice. Although several book chapters have been published about pulse surveys (e.g. Colihan \& Waclawski, 2006; Jolton \& Klein, 2020), a recent Google Scholar search resulted in only two published journal articles on the topic (Welbourne, 2016; Winton \& Palmer, 2018). Some additional studies have acknowledged the use of pulse surveys (e.g., Van Rooy et al., 2011) but available research is far outnumbered by articles and case studies published by survey vendors and the popular press. 
Without a basis of empirical evidence to rely on, scientist-practitioners may be left to rely on less credible sources when tasked with designing or implementing a pulse survey program (Delmhorst, 2018). This imbalance mirrors a broader research-practice divide regarding many popular talent management practices such as Lean management (Balzer et al., 2019). Rotolo and colleagues (2018) warned that the adoption of novel survey methods without a foundation of research evidence potentially leads to poor results and disinterest in organizational surveys in the long run.

Despite a lack of targeted studies on pulse surveys, there is a wealth of research on job attitudes which may be relevant to understanding the potential limitations of pulse surveys. For example, past studies have observed meaningful fluctuations in within-person engagement or other job attitudes over short periods of time (Bakker, 2014). Likewise, research have also observed "honeymoon" and "hangover" effects where job attitudes are most positive among newly hired employees but gradually decrease over time (Boswell et al., 2009) but may also increase slightly with age (Riza et al., 2018). However, decades of research has reported that job attitudes remain relatively stable between-persons over time (e.g., Staw \& Cohen-Chrash, 2005). In support of the dispositional approach to job attitudes, stable personality traits often share large proportions of variance in different attitudes. Meta-analytic research has found that personality traits combine to account for up to $48 \%$ of the variance in job attitudes, such as employee engagement (Young et al., 2018) or job satisfaction (Steel et al., 2019), as well as over 60\% of subjective well-being in general (Steel et al., 2008). These personality linkages are also is theorized to explain observed genetic correlations with job attitudes (Hahn et al., 2016). Other researchers propose other mechanisms, such as opponent process theory, by which job attitudes may experience minor fluctuations in the short-term but tend to return to a stable baseline over 
time (Bowling et al., 2005). There is also evidence for individual differences in the strength of their own job attitudes which may further limit variability over time (Schleicher et al., 2015). Based on these findings, it is uncertain whether more frequent, longitudinal pulse surveys can detect useful changes in employee attitudes, perceptions or behavior.

In addition to concerns about the relative stability of job-related attitudes, it is also uncertain whether pulse surveys are sensitive enough to detect meaningful differences between units or teams. Although there has been much research regarding within-person changes in job attitudes, in practice, organizational survey data are generally analyzed at the group or aggregate level (Harter \& Schmidt, 2006). Along these lines, researchers have made great advances in understanding how attitudes and perceptions of individual employees emerge to form grouplevel climate and other related constructs (Schneider et al., 2013). Bliese and colleagues (2019) identified that survey researchers and practitioners rarely consider the proportion of betweengroup variance when developing or evaluating organizational survey items. Even among the best performing items, less than $20 \%$ of the variability in item responses can be explained by grouplevel factors (as calculated using ICC(1) estimates). This problem may be further exacerbated by the use of single-item measures. Single-item measures may be adequate for measuring some constructs (Fisher et al., 2016) but this practice reduces reliability which can further minimize the proportion of between-group variability in scores. Therefore, the abbreviated structure of pulse surveys may act to minimize differences between groups.

\section{Present Study}

The goal of the present study is to report the results of a four-wave pulse survey program that was implemented within a healthcare organization. Pulse surveys are quickly becoming a common practice in many organizations and offer several advantages compared to traditional, 
large-scale organizational surveys. Despite their growing popularity, however, there is little empirical research to help scientist-practitioners determine the best practices for pulse surveys. Even though pulse surveys are attractive as a means to gather and respond to feedback more quickly, it is unclear how the limitations of this method may potentially harm the reliability or validity of survey data. Therefore, this study was designed to help bridge this growing researchpractice gap and to empirically observe the potential limitations of pulse surveys.

\section{Method}

\section{Participants}

Data were collected as part of a pulse survey program conducted at a regional hospital of roughly 400 employees. All hospital staff, excluding physicians, were eligible to participate in the survey program (between 304 and 360 staff members across waves). Four surveys were administered between the months of January and August. Some employees were only recruited to participate in the final three survey waves (e.g., radiology and respiratory staff). Each survey was developed by internal HR staff based on a literature search of similar construct measures and administered using an online survey building platform (Checkbox). Hospital employees were each sent an anonymous link to access the survey from HR staff. No identifying information was collected from employees. In each survey, participants were asked to identify the option that best described their current role at the hospital. Results were reported for nine to eleven different job roles (Table 1). Employees were given one week to participate.

Participation rates for each survey wave ranged from $42 \%$ (wave 4 ) to $54 \%$ (wave 3 ) of eligible staff. These values were used to calculate the overall margin of error for each survey using the formula reported by Colihan and Waclawski (2006). To estimate the margin of error in 
Likert-scale terms (scores ranging from 1-5), we assumed a normal distribution in item responses (variance $=1.04$ ). This yielded margin of error estimates which ranged from \pm .10 to .12 . Often, survey responses are also reported as percent favorable (Brown, 2020). For this metric, margin of error estimates ranged from \pm 4.8 to 6.2 percentage points.

\section{Survey Design}

Surveys were designed in order to test out two different survey methodologies as part of a pilot program. Each survey contained between three and five total survey questions. Using the taxonomy defined by Jolton and Klein (2020), the present study used a combination of censusbased action tracking and ad-hoc survey items. The primary goal of census-based action tracking pulses are to track action or movement in employee sentiment over time. Census-based pulsing involves the repeated measurement of a key variable (e.g., employee engagement) across the entire employee population. This variable is consistently measured at multiple time points in order to observe longitudinal trends in individual or team scores. Organizations have used this methodology in practice to detect seasonal trends in employee attitudes (Colihan \& Waclawski, 2006) or to monitor changes in motivation within work teams (Power, 2016).

In contrast, ad hoc surveys are designed to assess important, individual topics or initiatives at a single point in time. Rather than emphasizing longitudinal trends or analyses, ad hoc surveys are intended to measure a specific topic during the time between large-scale census surveys. For example, ad hoc surveys can be used to follow up on specific concerns that were identified within the previous census survey or to evaluate a recent organizational change. This methodology allows organizations to receive feedback more quickly than waiting to conduct the annual or biannual organizational survey. In the present study, participants were asked one or two ad hoc survey questions during each wave. The content for these questions were determined 
by responses to previous rounds of employee comments or local concerns identified within the hospital's leadership team.

\section{Measures}

State engagement was measured using a single item during each wave. Macey and Schneider (2008) defined state engagement as a blend of job satisfaction, involvement, and commitment but with a greater emphasis on affectivity. Participants were asked to respond to this question using a five-point, Emoji response scale (Figure 1). These scale anchors were originally designed by Phan and colleagues (2019) and observed to adequately replace verbal Likert-style response anchors in a measure of vocational interests. Similar Emoji-based response scales are commonly used by prominent customer and employee survey firms (e.g., Happy or Not; Owen, 2018). This methodology has also been used in provide a valid measure of affective job satisfaction in earlier research (Kunin, 1955).

Along with the affective engagement item, one to two additional questions were administered during each wave. In the first wave, one item measuring the opportunity to participate in decision making was administered. This item was found to be a key engagement driver based on the most recent organizational survey. In the second wave, employees were asked one question about supervisor support (adapted from Greenhaus et al., 1990). In the third wave, staff were asked two questions about perceived safety at the hospital. Responses to these items were strongly correlated $(r=.59)$ and combined to provide a composite measure. Lastly, staff were asked two questions about their recent performance appraisal in the fourth wave. One item was designed to measure satisfaction with the appraisal process relative to the prior year since a new review process had been implemented. The second item asked staff to indicate 
whether their supervisor had explained the basis for changes in pay (adapted from Jones et al., 1999). All survey questions are reported in the Appendix.

\section{Results}

\section{Effects of Group and Time on Engagement Ratings}

To observe the variability in affective engagement ratings over time and between work units, ratings were analyzed using a two-way analysis of variance (ANOVA) model. Each engagement rating was paired with a time variable (wave at which the item was administered) and a work unit variable (self-identified job role). This provided a way to calculate the proportion of variance in engagement ratings that could be accounted for by time and work unit. However, a truly repeated-measures ANOVA model was not possible to estimate because individual responses could not be linked to a single individual. This meant that any withinperson variance in ratings would be misspecified as error variance. Despite this limitation, the ANOVA model was still sufficient for observing the proportion of between-group and betweenwave variability in ratings. An interaction term (work unit * time) was also included in order to explore for differences in engagement trends over time between groups.

Both time $(F(3,623)=5.09, p=.002)$ and work unit $(F(10,623)=5.24, p<.001)$ explained significant variance in engagement ratings. Using Tukey's HSD to explore pairwise comparisons, engagement was significantly higher during waves 3 and 4 compared to wave 1

(Figure 2). However, there was no meaningful change in overall engagement between sequential survey waves. Overall differences between work units accounted for nearly four times the amount of engagement rating variance (partial $\eta^{2}=.08$ ) compared to differences between time points (partial $\eta^{2}=.02$ ). The hospital leadership team (Administration) was generally more 
highly engaged compared to most other work units. Yet, there were practically no other differences in engagement between individual work units. There was also no meaningful interaction between time and work unit $(F(11,627)=0.64, p=.79)$. This result indicates that no substantial differences in engagement trends over time could be detected between work units (Figure 3).

\section{Group and Individual-Level Effects for Each Survey}

Next, a separate set of analyses were conducted based on the response data gathered within each survey wave. The proportion of between-group variance for each survey item was estimated by calculating ICC(1) as recommended by Bliese and colleagues (2019). Although there was practically no group effect on engagement ratings in the first wave, ICC(1) estimates ranged from .10 to .13 across the remaining three waves (Table 2). Similar ICC(1) values were also found for each of the additional survey items administered in each wave. The largest group effects were found for satisfaction with performance reviews $(\operatorname{ICC}(1)=.18)$, and opportunity to participate in decision making $(\operatorname{ICC}(1)=.11)$. On the other hand, basically no group effect was observed for perceived workplace safety $(\operatorname{ICC}(1)=.03)$. Overall, most of the observed ICC $(1)$ values represent a medium effect of work group on individual responses according to guidelines reported by LeBreton and Senter (2008). However, these effects suggest that most of the variability in item responses can be explained by differences among individuals and not necessarily by group characteristics.

Individual engagement ratings were strongly related to many of the ad-hoc survey items administered within each survey wave (Table 3). Engagement was most strongly related to opportunities to participate in decision making $(r=.55)$ and perceived supervisor support $(r=$ $.50)$. These results suggest that responses to items designed to assess narrowly defined employee 
experiences or perceptions may be largely influenced by more general feelings of engagement or satisfaction. Assuming a reliability of .70 reported in a review of single-item measures by Wanous et al.(1997) and a reliability of .66 for a similar measure of affective engagement (Kunin, 1955), up to $65 \%$ of the reliable variance in each of these ad-hoc survey items could possibly be explained by engagement ratings (corrected $\rho=.81$ ). Slightly weaker, yet strong correlations were also found for procedural justice in pay decisions $(r=.37)$ and perceived workplace safety $(r=.24)$. These results evoke past research indicating a positive manifold across various forms of job attitudes (e.g., Newman \& Harrison, 2008; Shuck et al., 2017). For example, the twelve items in the Gallup Q12 survey are designed to measure different workplace experiences but a dominant, general factor typically accounts for most of the item variance (Harter et al., 2010). Although individual survey items may appear to target narrowly defined workplace concerns or topics, their face validity alone is not evidence of discriminant validity from more generalized job attitudes.

\section{Discussion}

In the present study, four waves of pulse surveys were deployed to employees of a regional hospital. Results indicate that only modest changes in state engagement could be detected over a period of eight months. Even with typical participation rates for most monthly, organizational surveys (Rotolo et al., 2020), practically no differences in engagement could be detected between job roles. There were also no differences in longitudinal trends in engagement between job roles. These results suggest either that group engagement levels remained relatively stable over time or that there was not enough variability in single-item ratings to detect differences between roles. ICC(1) estimates indicated useful group-level effects for engagement 
(between 10-13\% between-group variance in waves 2-4) but most of the variability could not be accounted for by time or group variables. Instead, most of the variability in responses are likely due to a combination of individual-level factors or measurement error.

\section{Implications for Practice and Directions for Future Research}

If current trends persist, more and more organizations will continue to adopt pulse surveys into practice (Rotolo et al., 2020). Therefore, further longitudinal research on changes in group-level measures over time is important to inform best practices. Pulse surveys are often marketed as a way of tracking real-time changes in employee sentiment (e.g., TINYpulse, n.d.) however much of the variability in responses over time could be caused by random measurement error (Thoresen et al., 2003). In addition, although researchers have linked substantive withinperson changes in engagement or job stress to important work outcomes (e.g., Ilies et al., 2017), these results may not generalize to group or aggregate levels. Cucina and colleagues (2020) recently observed that unit-level survey results exceeded test-retest reliabilities of .80 when comparing scores up to three years apart. These findings were also fairly consistent across different survey topics (e.g., job satisfaction, supervisor, team, leadership) suggesting that there was little meaningful change in group attitudes over that time.

Another important challenge for researchers and practitioners is to better understand how organizations can effectively keep up with the increased frequency of pulse surveys. Past work indicates that organizations often struggle to take timely action based on annual or biannual organizational surveys (e.g., Kraut, 2006). This problem becomes considerably more challenging if organizations are now tasked with reviewing and responding to additional surveys within a shorter period of time. Even though many new technologies provide the means to share survey results in real-time, leaders and managers may be reluctant to provide open access to results to 
all employees. In the present study, leaders were often hesitant to share survey results without first having the opportunity to review and summarize the results with managers. The reporting process first began by meeting with the leadership team after analyzing the survey results. Afterwards, the leadership team would present the result to a monthly meeting for all managers at the hospital. In result, employees typically needed to wait at least a couple of weeks before receiving feedback about the survey. Although collecting survey data more frequently is appealing to many, this also requires more frequent action in response to survey results. This is critical as failing to act on survey results can be more counterproductive than failing to share the basic survey results at all (Church \& Oliver, 2006). Thus, scientist-practitioners need to establish clear expectations about how pulse survey data will be used and how quickly employees and managers can expect to share results and take follow-up action.

Given these statistical and practical limitations, it is unclear how much value pulse surveys can provide to organizations. Although pulses are often identified as only a supplement to census-based surveys (e.g., Wellbourne, 2016), some organizational stakeholders may be looking to shift to pulse surveys due to dissatisfaction with the costs of traditional methods. Instead, pulse surveys appear ill-equipped to provide much beyond an immediate, high-level, perspective on a select few concepts or issues. Much of the past research and practice of employee surveys has focused on the importance of using surveys as a strategic tool for driving organizational change (Schneider et al., 1996). In a recent example, Schiemann and Seibert (2017) documented the evidence-based use of employee surveys to identify unique issues faced by regional units, better understand the importance of training in reducing turnover, and to inform the redesign of regional manager roles. To achieve this level of success, however, required a rich collection of data that allows for analysis across multiple levels and several 
actionable variables. Without a broader strategy or process for evaluating and taking action on survey results, it seems unlikely that the administration of more frequent, shorter pulse surveys alone will help drive successful change efforts.

Instead, a better application of pulse surveys could be to focus on open-response comments rather than close-ended survey items. This approach is more qualitative than quantitative but could help identify important topics or concerns among employees. Although the use of open-ended comments has been limited in the past due to the cost of reading and coding responses (Krosnick \& Presser, 2010), recent technological advances have enabled researchers and practitioners to analyze large bodies of open-response data using natural language processing (Dutta \& O'Rourke, 2020). Several NLP tools are presently available for use with open-source statistical packages (e.g., R; Kumar \& Paul, 2016) and many third-party survey vendors offer text analytics as part of their services. The use of text analysis has also been expanding into other areas of organizational practice including performance appraisal (Speer, 2020) and selection testing (Lievens et al., 2019). Open-response comments could be analyzed in order to identify ideas and concepts to be further investigated in subsequent surveys. This may help organizations design surveys that feel more relevant to employees while indicating that the organization is using employee feedback to learn more about concerns expressed within the pulse surveys.

\section{Limitations}

There are a few limitations that should be acknowledged when interpreting the results of the present study. First, all four surveys were anonymous which made it impossible to estimate the proportion of within-person variance in engagement responses. Past research has found that within-person factors may account for nearly half of the variability in engagement or similar job attitudes (Bakker, 2014). This suggests that our estimates of error variance are likely inflated 
since they confound within-person variability with unsystematic error. However, most survey data in practice are analyzed and reported in aggregate in order to ensure that employee responses are confidential. Second, these results were obtained from hospital employees within a single organization. Even though most of the survey items were not specific to health care or medicine, it is possible that these results may not generalize to other workplace settings. Lastly, these survey results are based on a pilot program that only involved a population of 360 employees across eleven self-reported work roles. These results may be most relevant to moderately sized organizations (fewer than 500 employees) In contrast, larger organizations may be capable of gathering more reliable measures from pulse surveys due larger sample sizes. In either case, the results of the present study may still be informative in illustrating the difficulty of detecting reliable between-group differences when using brief survey measures in practice.

\section{Conclusions}

The results of the present study highlight several limitations of conducting pulse surveys. Despite the allure of collecting more frequent feedback from employees, the typical features of pulse surveys limit the reliability by relying on short, single-item measures. These measures also yield little between-group variance in response which makes it difficult to identify meaningful differences between work units or departments. In most cases, results may only be representative of the entire organization. This may be problematic if leaders are expecting to analyze work unit results as typical in traditional, census-based surveys. Thus, scientist-practitioners should carefully consider these limitations when designing or implementing pulse survey programs. Continued research is needed in order to identify the optimal uses for this method as a supplement to large-scale, organizational surveys. 


\section{References}

Bakker, A. B. (2014). Daily fluctuations in work engagement: An overview and current directions. European Psychologist, 19, 227-236. https://doi.org/10.1027/1016$\underline{9040 / a 000160}$

Balzer, W. K., Brodke, M. H., Kluse, C., \& Zickar, M. J. (2019). Revolution or 30-year fad? A role for I-O psychology in Lean management. Industrial and Organizational Psychology: Perspectives on Science and Practice, 12, 215-233. https://doi.org/10.1017/iop.2019.23

Bliese, P. D., Maltarich, M. A., Hendricks, J. L., Hofmann, D. A., \& Adler, A. B. (2019). Improving the measurement of group-level constructs by optimizing between-group differentiation. Journal of Applied Psychology, 104, 293-302. https://doi.org/10.1037/ap10000349

Boswell, W. R., Shipp, A. J., Payne, S. C., \& Culbertson, S. S. (2009). Changes in newcomer job satisfaction over time: Examining the pattern of honeymoons and hangovers. Journal of Applied Psychology, 94, 844-858. https://doi.org/10.1037/a0014975

Bowling, N. A., Beehr, T. A., Wagner, S. H., \& Libkuman, T. M. (2005). Adaptation-level theory, opponent process theory, and dispositions: An integrated approach to the stability of job satisfaction. Journal of Applied Psychology, 90, 1044-1053. https://doi.org/10.1037/0021-9010.90.6.1044

Brown, M. I. (2020). Comparing the validity of net promoter and benchmark scoring to other commonly used employee engagement metrics. Human Resource Development Quarterly. Advance online publication. https://doi.org/10.1002/hrdq.21392 
Cappelli, P. (2020 August 1). It's time to get rid of employee surveys. Wall Street Journal. Retrieved from https://www.wsj.com/articles/its-time-to-get-rid-of-employee-surveys-

\section{3}

Cappelli, P., \& Tavis, A. (2018). HR goes agile. Harvard Business Review, 96(2), 46-52.

Church, A. H., \& Oliver, D. H. (2006). The importance of taking action, not just sharing survey feedback. In A. Kraut (Ed.), Getting action from organizational surveys: New concepts, technologies, and applications (pp. 102-130). Jossey-Bass.

Church, A. H., \& Waclawski, J. (2020). Rediscovering the art of surveys for organizational change. In W. H. Macey \& A. A. Fink (Eds.), Employee surveys and sensing: Challenges and opportunities (pp. 357-373). Oxford University Press.

Colihan, J., \& Waclawski, J. (2006). Pulse surveys: A limited approach with some unique advantages. In A. Kraut (Ed.), Getting action from organizational surveys: New concepts, technologies, and applications (pp. 264-293). Jossey-Bass.

Cucina, J.M., Burtnick, S.K., Byle, K.A., Hayes, T.L., \& Pillion, H.K. (2020). A 14-year Analysis of Unit-level Job Satisfaction/Employee Engagement Score Stability. Poster presented at the 35th meeting of the Society for Industrial and Organizational Psychology, Austin, TX.

Delmhorst, F. (2018). What if any science will do? Industrial and Organizational Psychology: Perspectives on Science and Practice, 11, 236-240. https://doi.org/10.1017/iop.2018.11

Dutta, S., \& O’Rourke, E. M. (2020). Open-ended questions: The role of natural language processing and text analytics. In W. H. Macey \& A. A. Fink (Eds.), Employee surveys and sensing: Challenges and opportunities (pp. 202-218). Oxford University Press. 
Fisher, G. G., Matthews, R. A., \& Gibbons, A. M. (2016). Developing and investigating the use of single-item measures in organizational research. Journal of Occupational Health Psychology, 21, 3-23. https://doi.org/10.1037/a0039139

Greenhaus, J. H., Parasuraman, A., \& Wormley, W. M. (1990). Effects of race on organizational experiences, job performance evaluations, and career outcomes. Academy of Management Journal, 33, 64-86. https://doi.org/10.5465/256352

Hackman, J. R. (2003). Learning more by crossing levels: Evidence from airplanes, hospitals, and orchestras. Journal of Organizational Behavior, 24, 905-922. https://doi.org/10.1002/job.226

Hahn, E., Gottschling, J., Konig, C. J., \& Spinath, F. M. (2016). The heritability of job satisfaction reconsidered: Only unique environmental influences beyond personality. Journal of Business and Psychology, 31, 217-231. https://doi.org/10.1007/s10869-0159413-x

Harrison, M. (2018, November 29). How a U.S. health care system uses 15-minute huddles to keep 23 hospitals aligned. Harvard Business Review. Retrieved from: https://hbr.org/2018/11/how-a-u-s-health-care-system-uses-15-minute-huddles-to-keep23-hospitals-aligned

Harter, J. K., \& Schmidt, F. L. (2006). Connecting employee satisfaction to business unit performance. In A. Kraut (Ed.), Getting action from organizational surveys: New concepts, technologies, and applications (pp. 33-52). Jossey-Bass.

Harter, J. K., Schmidt, F. L., Asplund, J. W., Killham, E. A., \& Agrawal, S. (2010). Causal impact of employee work perceptions on the bottom line of organizations. Perspectives on Psychological Science, 5, 378-389. https://doi.org/10.1177/1745691610374589 
Ilies, R., Liu, X.-Y., Liu, Y., \& Zheng, X. (2017). Why do employees have better family lives when they are highly engaged at work? Journal of Applied Psychology, 102, 956-970. https://doi.org/10.1037/ap10000211

Jolton, J. A., \& Klein, C. (2020). Exploring the universe of pulse surveys and continuous listening opportunities. In W. H. Macey \& A. A. Fink (Eds.), Employee surveys and sensing: Challenges and opportunities (pp. 53-67). Oxford University Press.

Jones, F. F., Scarpello, V., \& Bergmann, T. (1999). Pay procedures - What makes them fair? Journal of Occupational and Organizational Psychology, 72, 129-145. https://doi.org/10.1348/096317999166554

Kraut, A. I. (2006). Moving the needle: Getting action after a survey. In A. Kraut (Ed.), Getting action from organizational surveys: New concepts, technologies, and applications (pp. 132). Jossey-Bass.

Krosnick, J. A., \& Presser, S. (2010). Question and questionnaire design. In P V. Marsden \& J. D. Wright (Eds.), Handbook of survey research (pp. 263-313). Emerald.

Kumar, A., \& Paul, A. (2016). Mastering text mining with R. Packt Publishing.

Kunin, T. (1955). The construction of a new type of attitude measure. Personnel Psychology, 8 , 65-77. https://doi.org/10.1111/j.1744-6570.1955.tb01189.x

LeBreton J. M., \& Senter, J. L. (2008). Answers to 20 questions about interrater reliability and interrater agreement. Organizational Research Methods, 11, 815-852. https://doi.org/0.1177/1094428106296642

Lievens, F., Sackett, P. R., Dahlke, J. A., Oostrom, J. K., \& De Soete, B. (2019). Constructed response formats and their effects on minority-majority differences and validity. Journal of Applied Psychology, 104, 715-726. https://doi.org/10.1037/apl0000367 
Macey, W. H., \& Fink, A. A. (2020). Surveys and sensing: Realizing the promise of listening to employees. In W. H. Macey \& A. A. Fink (Eds.), Employee surveys and sensing: Challenges and opportunities (pp. 1-19). Oxford University Press.

Macey, W. H., \& Schneider, B. (2008). The meaning of employee engagement. Industrial and Organizational Psychology: Perspectives on Science and Practice, 1, 3-30. https://doi.org/10.1111/j.1754-9434.2007.0002.x

Mastrangelo, P. M. (2020). Improving the design and interpretation of sample surveys in the workplace. In W. H. Macey \& A. A. Fink (Eds.), Employee surveys and sensing: Challenges and opportunities (pp. 38-52). Oxford University Press.

Newman, D. A., \& Harrison, D. A. (2008). Been there, bottled that: Are state and behavioral work engagement new and useful construct "wines"? Industrial and Organizational Psychology: Perspectives on Science and Practice, 1, 31-35. https://doi.org/10.1111/j.1754-9434.2007.00003.x

Owen, D. (2018, January 29). Customer satisfaction at the push of a button. New Yorker. Retrieved from https://www.newyorker.com/magazine/2018/02/05/customer-satisfactionat-the-push-of-a-button

Phan, W. M. J., Amrhein, R., Rounds, J., \& Lewis, P. (2019). Contextualizing interest scales with emojis: Implications for measurement and validity. Journal of Career Assessment, 27, 114-133. https://doi.org/10.1177/1069072717748647

Power, B. (2016, May 24). Why John Deere measures employee morale every two weeks. Harvard Business Review. Retrieved from https://hbr.org/2016/05/why-john-deeremeasures-employee-morale-every-two-weeks 
Rigby, D. K., Elk, S., \& Berez, S. (2020, May/June). The agile C-suite. Harvard Business Review. Retrieved from https://hbr.org/2020/05/the-agile-c-suite

Riza, S. D., Ganzach, Y., \& Lui, Y. (2018). Time and job satisfaction: A longitudinal study of the differential roles of age and tenure. Journal of Management, 44, 2558-2579. https://doi.org/10.1177/0149206315624962

Rotolo, C. T., Church, A. H., Adler, S., Smither, J. W., Colquitt, A. L., Shull, A. C., Paul, K. B., \& Foster, G. (2018). Putting an end to bad talent management: A call to action for the field of industrial and organizational psychology. Industrial and Organizational Psychology: Perspectives on Science and Practice, 11, 176-219. https://doi.org/10.1017/iop.2018.6

Rotolo, C. T., Fleck, C. R., \& Shepherd, B. (2020). Current and future trends in employee survey practice: A view from employee survey practitioners. In W. H. Macey \& A. A. Fink (Eds.), Employee surveys and sensing: Challenges and opportunities (pp. 425-442). Oxford University Press.

Schiemann, W. A., \& Seibert, J. H. (2017). Winning the HRM evidence-based impact award lessons learned: A conversation with key stakeholders to the process. Industrial and Organizational Psychology: Perspectives on Science and Practice, 10, 314-326.

\section{https://doi.org/10.1017/iop.2017.25}

Schleicher, D. J., Smith, T. A., Casper, W. J., Watt, J. D., \& Greguras, G. J. (2015). It's all in the attitude: The role of job attitude strength in job attitude-outcome relationships. Journal of Applied Psychology, 100, 1259-1274. https://doi.org/10.1037/a0038664 
Schneider, B., Ashworth, S. D., Higgs, A. C., \& Carr, L. (1996). Design, validity, and use of strategically focused employee attitude surveys. Personnel Psychology, 49, 695-705. https://doi.org/10.1111/j.1744-6570.1996.tb01591.x

Schneider, B., Ehrhart, M. G., \& Macey, W. H. (2013). Organizational climate and culture. Annual Review of Psychology, 64, 361-388. https://doi.org/10.1146/annurev-psych-

\section{$113011-143809$}

Schneider, B., Yost, A. B., Kropp, A., Kind, C., \& Lam, H. (2018). Workforce engagement: What is it, what drives it, and why it matters for organizational performance. Journal of Organizational Behavior, 39, 462-480. https://doi.org/10.1002/job.2244

Shuck, B., Nimon, K., \& Zigarmi, D. (2017). Untangling the predictive nomological validity of employee engagement: Partitioning variance in employee engagement using job attitude measures. Group \& Organization Management, 42, 79-112. https://doi.org/10.1177/1059601116642364

Silverman, R. E. (2014, December 2). Are you happy at work? Bosses push weekly polls. Wall Street Journal. Retrieved from http://www.wsj.com/articles/more-bosses-use-shortfrequent-polls-to-measure-morale-1417550446

Speer, A. B. (2020). Scoring dimension-level job performance from narrative comments: Validity and generalizability when using natural language processing. Organizational Research Methods. https://doi.org/10.1177/1094428120930815

Staw, B. M., \& Cohen-Charash, Y. (2005). The dispositional approach to job satisfaction: More than a mirage, but not yet an oasis. Journal of Organizational Behavior, 26, 59-78. https://doi.org/10.1002/job.299 
Steel, P., Schmidt, J., Bosco, F., \& Uggerslev, K. (2019). The effects of personality on job satisfaction and life satisfaction: A meta-analytic investigation accounting for bandwidthfidelity and commensurability. Human Relations, 72, 217-247. https://doi.org/10.1177/0018726718771465

Steel, P., Schmidt, J., \& Shultz, J. (2008). Refining the relationship between personality and subjective well-being. Psychological Bulletin, 134, 138-161. https://doi.org/10.1037/0033-2909.134.1.138

TINYpulse (n.d.). The advanced guide to employee pulsing. Retrieved online from: https://www.tinypulse.com/\#advanced-pulsing-guide

Thorsen, C. J., Kaplan, S. A., Barsky, A. P., Warren, C. R., \& de Chermont, K. (2003). The affective underpinnings of job perceptions and attitudes: A meta-analytic review and integration. Psychological Bulletin, 129, 914-945. https://doi.org/10.1037/00332909.129.6.914

Van Rooy, D. L., Whitman, D. S., Hart, D., \& Caleo, S. (2011). Measuring employee engagement during a financial downturn: Business imperative or nuisance? Journal of Business and Psychology, 26(2), 147-152. https://doi.org/10.1007/s10869-011-9225-6

Welbourne, T. M. (2016). The potential of pulse surveys: Transforming surveys into leadership tools. Employment Relations Today, 43, 33-39. https://doi.org/10.1002/ert.21548

Winton, S., \& Palmer, S. N. (2018). It's about time: Measuring the pulse of engagement. Strategic HR Review, 17, 164-165. https://doi.org/10.1108/SHR-01-2018-0010

Young, H. R., Glerum, D. R., Wang, W., \& Joseph, D. L. (2018). Who are the most engaged at work? A meta-analysis of personality and employee engagement. Journal of Organizational Behavior, 39, 1330-1346. https://doi.org/10.1002/job.2303 
Table 1.

Participants by Survey Wave and Job Role

\begin{tabular}{lrrrr}
\hline & Wave 1 & Wave 2 & Wave 3 & Wave 4 \\
\hline Administration & 5 & 7 & 6 & 5 \\
Environmental Services (EVS) & 16 & 20 & 23 & 15 \\
Facilities & 4 & 7 & 5 & 5 \\
Finance & 4 & 4 & 6 & 5 \\
Food Services & 6 & 8 & 3 & 3 \\
Laboratory & 13 & 12 & 13 & 12 \\
Nursing & 57 & 70 & 74 & 62 \\
Other, Clinical & 8 & 14 & 24 & 10 \\
Other, Non-Clinical & 23 & 17 & 18 & 15 \\
Radiology & & 12 & 8 & 9 \\
Respiratory & & 6 & 6 & 7 \\
Overall Participation (\%) & $\mathbf{1 3 6 ( 4 3 \% )}$ & $\mathbf{1 7 7} \mathbf{( 5 0 \% )}$ & $\mathbf{1 8 6}(\mathbf{5 3 \% )}$ & $\mathbf{1 5 1} \mathbf{( 4 2 \% )}$ \\
\hline
\end{tabular}


Table 2.

Engagement Results by Survey Wave

\begin{tabular}{lcccccc}
\hline & $\mathrm{M}$ & $\mathrm{SD}$ & $\begin{array}{c}\text { Percent } \\
\text { Favorable }\end{array}$ & $\mathrm{ICC}(1)$ & $d$ Wave 1 & $\begin{array}{c}d \\
\text { Previous }\end{array}$ \\
\hline $\begin{array}{l}\text { Wave 1 } \\
(n=136)\end{array}$ & 3.21 & 1.23 & $50 \%$ & $\begin{array}{c}.02 \\
(-.04, .22)\end{array}$ & & \\
$\begin{array}{l}\text { Wave 2 } \\
(n=177)\end{array}$ & 3.44 & 1.03 & $51 \%$ & $\begin{array}{c}.13 \\
(.03, .37)\end{array}$ & 0.21 & 0.21 \\
$\begin{array}{l}\text { Wave 3 } \\
(n=186)\end{array}$ & 3.61 & 0.94 & $62 \%$ & $\begin{array}{c}.10 \\
(.01, .32)\end{array}$ & $0.37^{*}$ & 0.17 \\
$\begin{array}{l}\text { Wave 4 } \\
(n=151)\end{array}$ & 3.60 & 0.84 & $58 \%$ & $\begin{array}{c}.10 \\
(.00, .33)\end{array}$ & $0.37^{*}$ & -0.01 \\
\hline
\end{tabular}

Note. $\mathrm{M}=$ mean; $\mathrm{SD}=$ standard deviation; Percent favorable is the proportion of respondents who selected either of the top two response options; ICC = interclass correlation; values in brackets represent $95 \%$ confidence intervals; $d$ Wave $1=$ standardized mean difference compared to engagement at Wave $1 ; d$ Previous $=$ standardized mean difference compared to engagement at previous time point

$* p<.05$ 
Table 3.

Correlations between Engagement Ratings and Survey Items

\begin{tabular}{|c|c|c|c|c|c|}
\hline & M & SD & $\mathrm{ICC}(1)$ & $r$ & $\rho$ \\
\hline \multicolumn{6}{|l|}{ Wave 1} \\
\hline Participation in Decision Making & 4.18 & 1.60 & $\begin{array}{c}.11 \\
(.01, .39)\end{array}$ & $\begin{array}{c}.55 \\
(.42, .65)\end{array}$ & .81 \\
\hline \multicolumn{6}{|l|}{ Wave 2} \\
\hline Helpfulness of Supervisor Feedback & 4.07 & 1.52 & $\begin{array}{c}.08 \\
(.00, .29)\end{array}$ & $\begin{array}{c}.50 \\
(.38, .60)\end{array}$ & .74 \\
\hline \multicolumn{6}{|l|}{ Wave 3} \\
\hline Workplace Safety at the Hospital & 5.08 & 0.75 & $\begin{array}{c}.03 \\
(-.02, .19)\end{array}$ & $\begin{array}{c}.24 \\
(.10, .37)\end{array}$ & .35 \\
\hline \multicolumn{6}{|l|}{ Wave 4} \\
\hline Satisfaction with Performance Review ${ }^{a}$ & 3.46 & 1.05 & $\begin{array}{c}.18 \\
(.06, .46)\end{array}$ & $\begin{array}{c}.14 \\
(-.02, .29)\end{array}$ & .21 \\
\hline Procedural Justice in Pay & 4.24 & 1.50 & $\begin{array}{c}.10 \\
(.00, .33)\end{array}$ & $\begin{array}{c}.37 \\
(.16, .45)\end{array}$ & .54 \\
\hline \multicolumn{6}{|c|}{$\begin{array}{l}\text { Note. } \mathrm{M}=\text { mean; } \mathrm{SD}=\text { standard deviation; } \mathrm{CI}=\text { confidence interval. } \mathrm{ICC}(1)=\text { interclass } \\
\text { correlation, type } 1 . \text { These values can be interpreted as the proportion of between-group variance } \\
\text { in scores; Values in parentheses represent } 95 \% \text { confidence intervals; }{ }^{\mathrm{a}}=\text { item used a five-point } \\
\text { response scale (all other items used a six-point response scale); } \rho=\text { correlation between item anc } \\
\text { engagement rating after correcting for measurement error in the item (reliability estimate }=.70 \\
\text { from Wanous et al., 1997) and engagement (reliability estimate }=.66 \text { from Kunin, 1955). }\end{array}$} \\
\hline
\end{tabular}


How was your last month at work?
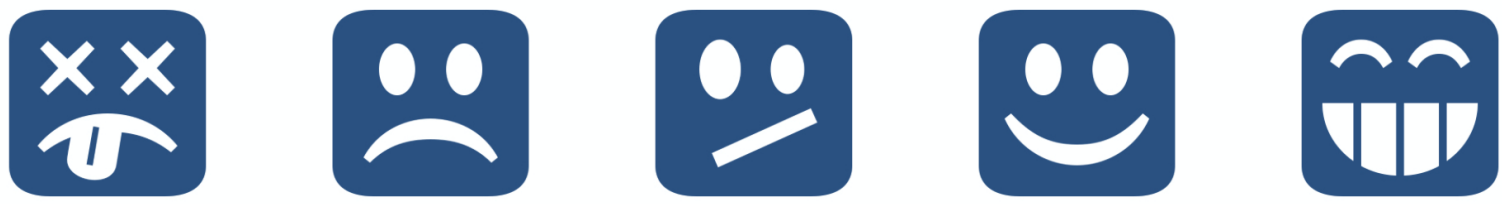

Figure 1. Engagement item used in all four pulse surveys. Response anchors were originally used by Phan and colleagues (2019) and are freely available for educational or commercial use. 

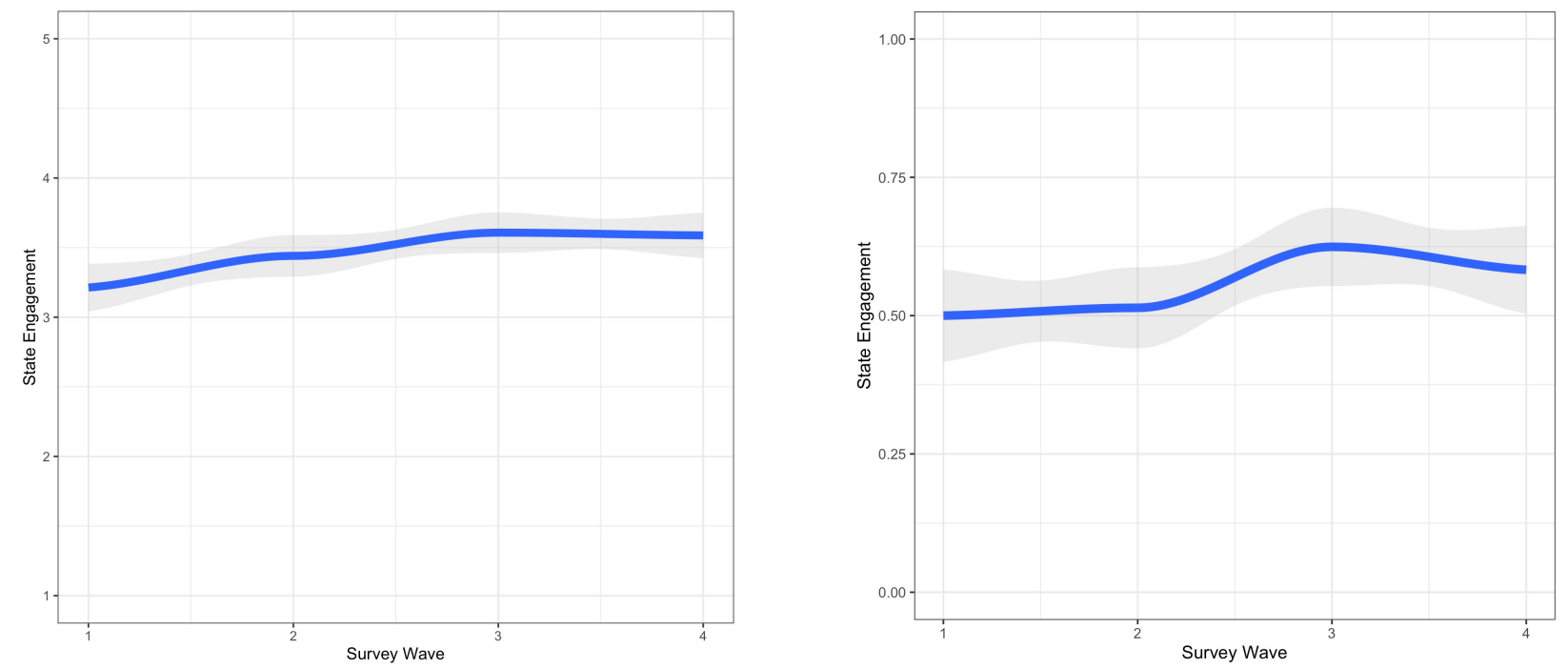

Figure 2. Overall Trend in Affective Engagement across Time. Average scores are reported on the left and percent favorable are reported on the right. Shaded areas represent the standard error in engagement scores at each time point. Compared to wave 1, mean engagement scores were higher in waves 3 and 4 . However, the changes in scores between waves 1-2, 2-3, and 3-4 did not reach statistical significance. 

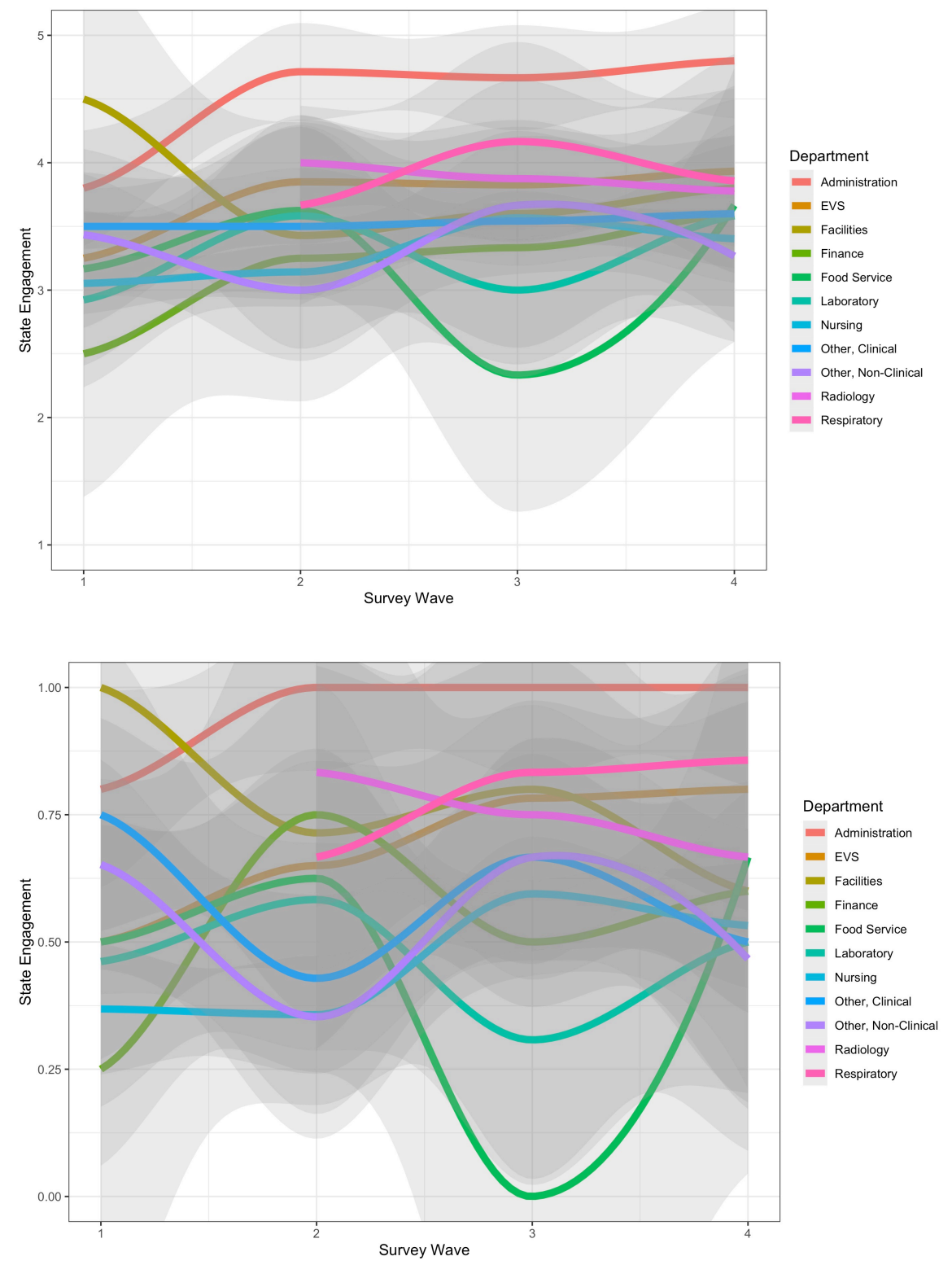

Figure 3. Trends in Affective Engagement across Time by Department. Average scores are reported in the top chart and percent favorable are reported below. The shaded areas represent the standard error in engagement scores at each time point. These results indicate that most of the between-group differences in engagement scores are overpowered by within-group variance in scores. Across all time points, Administration scored higher in engagement compared to most other departments but no other between-group differences reached statistical significance. 


\section{Appendix: Full Listing of Ad-Hoc Survey Items}

Wave 1

My supervisor gave me opportunities to participate in decisions that affected my work environment. [disagree/agree]

Wave 2

My supervisor gave me feedback last month that helped me do my job. [disagree/agree]

Wave 3

I always feel safe on the job at [the hospital]. [disagree/agree]

I always feel safe when traveling between the hospital and the parking lot. [disagree/agree]

Wave 4

Compared to last year, how would you rate the new performance review process? [much worse than last year / much better than last year]

My supervisor explained to me how my pay increase was decided. [disagree/agree] 